\title{
12 WHO HAS THE POWER OVER SPACES OF INNOVATION? The Role of Technology in ICT-Triggered Change Processes
}

\author{
Anneli Linde \\ Henrik C. J. Linderoth \\ Umeå School of Business \\ Umeå University \\ Umeå, Sweden
}

\begin{abstract}
ICT-triggered change processes are known to be unpredictable and technologies are not used the way designers or managers intend because of actor groups 'innovation when ICT is deployed. The examination of sources of innovation in ICT-triggered change processes has had a socio-cognitive bias toward learning and the way actors make sense of ICT. This paper addresses the role of technology for actors in spaces of innovation. The aim of the paper is to analyze how features of ICT shape spaces for innovation in ICT-triggered change processes. To achieve this, two longitudinal case studies of the deployment of two ICT systems are analyzed. By analyzing features as programs of action inscribed in an ICT, we conclude that programs of action can be grouped along the dimensions "use/not use," "what to do," and "how to do." These dimensions will shape actor groups' spaces of innovation and their potential influence on deployment of ICT. Furthermore, we address how inscribed programs of action shape the need for temporal alliances between actor groups during the deployment of an ICT system.
\end{abstract}

Keywords Organizational change, ICT, programs of action, inscriptions, actor network theory

Please use the following format when citing this chapter:

Linde, A., and Linderoth, H. C. J., 2008, in IFIP International Federation for Information Processing, Volume 287, Open IT-Based Innovation: Moving Towards Cooperative IT Transfer and Knowledge Diffusion, eds. León, G., Bernardos, A., Casar, J., Kautz, K., and DeGross, J. (Boston: Springer), pp. 211-226. 


\section{INTRODUCTION}

During the past few decades, information and communication technologies (ICTs) have been used as a means to change organizational work processes and structures. However, reaching an organizational transformation by implementing ICTs is known to be problematic and the technologies are not used as designers or managers intend. The slippage between designers' and managers' intentions and users' actual deployment of technology can be seen as a process of drifting. That is, the original goals and aims with a new IT system drift away from its original intention regardless of who defines the intention (Ciborra 1996). Technology drift may be a consequence of adaptations to circumstances in the context where the ICT is implemented, such as when technology projects are allowed to drift to suit different actors' needs (Holmström and Stadler 2001) or when disputes among actors involved need to be settled (Elbanna 2007). Drift can also occur when actor groups reinterpret the aim of implementing an ICT and thereby take control over the further deployment (Hanseth and Braa 1998). Drift can be regarded as a process of knowledge development and learning (Rosenberg 1982). However, in the management literature, drift of ICT-triggered change processes does not appear to be desirable. Processes are assumed to occur top-down in a controlled manner (Ciborra 2000), with the aim of at integrating all information into a system in order to reduce fragmentation and increase efficiency (Monteiro 2003). However, in practice, few ICTtriggered change initiatives are implemented in a controlled top-down mode. ICTtriggered changes also emerge from the bottom-up as a result of actors' appropriation over time of a new technology into their work practices (Orlikowski 1996). Whether implementation initiatives emerge top-down or bottom-up, new technologies never fit perfectly in an organization, implying that local adaptations are needed. This need for adaptations can also be seen as an occasion for innovation where deployment of a new ICT can trigger organizational innovation and product development (Boland et al. 2007). However, the examination of sources of innovation in ICT-triggered change processes can have a socio-cognitive bias toward learning and the way actors make sense of ICT. Research has paid limited attention to the role of ICT itself in these change processes (Monteiro and Hanseth 1995; Orlikowski and Yates 2006) and has not addressed the role technology plays in innovation with respect to change processes. Is there any relations between the characteristics of an ICT and different actor groups' possibilities to innovate in the change process? This question is legitimate to ask because technology designers delegate roles and competencies to human and nonhuman entities that comprise a sociotechnical network that is supposed to implement the change (Akrich 1992; Latour 1992). Hence, the delegation of roles and competencies, we claim, will shape the space for innovation in the network.

Accordingly, the aim of the paper is to analyze how features of ICT shape actor groups' options to innovate in ICT-triggered change processes. To achieve this aim, two longitudinal case studies of the deployment of two ICT systems are analyzed. In selecting our cases, we tried to identify cases where the features of the implemented ICT are dissimilar in order to create an enhanced understanding of how features of an ICT shape actor groups' spaces for innovation in a change process. 


\section{THEORETICAL POINT OF DEPARTURE}

In research on ICT-triggered changes processes, limited attention has been paid to the role ICT itself. Monteiro and Hanseth (1995) and Orlikowski and Iaccono (2001) both state that researchers need to be more specific about technological artefacts when analyzing the introduction of an ICT system into an organization and not take the technology for granted. They claim that this approach will shed light on critical impacts, or failure of impacts on different organizational levels. Taking the technology into consideration also raises the challenge of articulating the technology's characteristics (Orlikowski and Yates 2006) without reifying them through a form of contingent determinism (Bridgman and Wilmot 2006) and without reducing them to the social (Berg 1997). One path to move away from the determinist account is to recognize the understanding that members of a social group come to have of particular technological artefacts, expressed as technological frames (Orlikowski and Gash 1994). These include an actor group's shared understanding of the following:

- the technology's opportunities and function

- the motive or vision behind the adoption decisions and the technology's eventual value for the organization

- how the technology will be used day-to-day and possible or actual preconditions and consequences connected with technology use

The analysis of technological frames can help highlight how actor groups make sense of ICT or special aspects of ICT, unveiling actor groups' conceptions of the spaces of innovation. However, when analyzing technological frames, Davidson (2006) argues that context for examining technological frames needs to be expanded to the organizational fields to include cultural assumptions and institutional logics, reinforcing technological frames. Further, technology frames are continuously constructed and refined in practice through inferences of actors' past experiences as well as obtaining new knowledge emerging from actors' interactions with technology (Linderoth and Pellegrino 2005). How can we approach technology and its features in order to increase the understanding of actors' spaces for innovation?

We argue that a way of approaching technology features is to use the concept of inscriptions (Akrich 1992) as an analytical tool. Inscriptions refer to programs of actions inscribed in technological artefacts that originate from technology designers' assumptions about the potential user and the context for use. Technology designers' inscribed programs delegate roles and competencies to the components of a socio-technical network, including human and nonhuman entities of the system (Akrich 1992; Latour 1992). When a program of action is inscribed into a piece of technology, the technology could become an actor imposing its inscribed programs of action on its user (Monteiro 2000, p. 77). Thus, the mode in which ICT-triggered change processes unfold depends on programs of action inscribed in an ICT system and how actors, in the setting that would be transformed, act upon the inscribed programs of action.

How can we understand the inscribed programs of actions in practice? Let us consider a Web-based system for booking airline tickets. In this system, a wide array of assumptions about me as a user and the programs of actions that I have to perform if I should get my ticket are inscribed. It is assumed that I have a computer, I can use it, I 
would be able to read and understand the language on the Web pages, I can navigate the Internet, and I have a valid credit card. Furthermore, I have to go through a number of procedures to book my flight, selecting a flight, typing my name, e-mail address, credit card number, accept the terms of conditions, etc. The programs of actions are inscribed and I have to follow these restrictions if I want a ticket. But I have some degree of freedom concerning when and where I want to travel, which carrier I prefer (if I book via an Internet-based travel agent), which class of travel I would like (as long as my intentions are to take a flight between places with airports of decent size). Compare these programs of actions with inscribed programs of action in a paper clip. Briefly, the designer has assumed that I want to fold a paper pile of a certain thickness and that my hands and fingers are of certain size and strength. But the designer cannot inscribe any programs of action that govern me to use the clip in an intended way. On the contrary, it is just my fantasy that delimits my appropriation of the paper clip. If a power perspective is applied to these two cases, in the former case, technology designers together with the actors selling the airline tickets control via the system my actions when I want to order an airline ticket. In the latter case, I as a user have the power over how I use the paper clip and my spaces for innovation are rather large. In the former case, my spaces of innovation as a user are limited because programs of actions are strengthened by inscribing them into the system (Hanseth and Monteiro 1997). Hence programs of actions inscribed in technological artefacts can give me as a user a varying flexibility, or spaces of innovation, with regard to the actions I perform. But a crucial issue when it comes to ICT-triggered changes and the spaces of innovation in the process is if I use the ICT at all: Do I perform any action at all by means of the ICT, a precondition for the change process to unfold?

How are users imposed to use the ICT in order to achieve some kind of change? How are inscribed programs of action strengthened to trigger a change process with intended or unintended outcomes? By drawing on Hanseth and Montiero's (1997) analytical point of view, three ways of strengthening inscribed programs of action can be identified. First, programs of action can be linked to large and complex actor networks in the surroundings. For example, programs of actions inscribed in laws are strengthened by police, courts, and prisons to impose the desired behavior on me as a citizen. Second, a program action can be aligned with a surrounding actor network. For example, the program of action inscribed on signs in hotel bathrooms encourages me to reuse the towels (and save money for the hotel owner), aligning the company and guest with the growing consciousness of environmental issues. Third, a program of action can be strong in itself. However, from this perspective, we claim that programs of action are not per se strong. They are strengthened by removing alternative ways of action. For example, Ryan Air wants us as passengers to book the airline tickets via their Webpage. This program of action is strengthened by removing or complicating alternative programs of action. Have you, for example, seen a Ryan Air ticket office downtown? Furthermore, on the front Webpage, no contact information is given. That is a few clicks away. If I want to book my tickets via telephone, I am charged 30 cents per minute if I do not live in Ireland.

To conclude, programs of action inscribed in an ICT will have an impact on activities performed by means of the ICT. In this sense, more or less space for innovation is delegated to the user. Actions are performed as a matter of the options the user is directed to take or as a matter of not using the ICT. 


\section{DATA COLLECTION AND CASE DESCRIPTIONS}

Features of an ICT, in this paper, are regarded as programs of actions inscribed in an ICT and will have consequences for actor groups' spaces of innovation in an ICTtriggered change process. Accordingly, we tried to choose cases where the programs of action inscribed differ with regard to variations in the inscribed actions to perform by means of the ICT and variations in how inscribed actions are performed. Thus, on the surface, the cases appear quite dissimilar; however, they were chosen to demonstrate general situations when ICT is interpreted by actors creating networks of users conducting organizational changes.

The empirical base is from two ICT implementation projects aimed at organizational change. Both projects have been studied as longitudinal case studies over several years. The first case concerns the implementation of a project management model at Swedish customs, and the second concerns the implementation of telemedicine (video conferencing) systems in a Swedish health care organization.

\subsection{The Project Management Model Project}

One of the consequences of today's "projectified" society (Lundin and Söderholm 1995 ) is a trend toward a standardization of project activities by means of formalized, generic project management models, PMMs (Gunnarson et al. 2000). The rationale behind this development seems to be a quest for a common conceptual platform and work methods for all projects. One of today's well-known, commercially available, IT-based PMMs, PROPS, was originally developed by the telecom company Ericsson and applied in Ericsson subsidiaries worldwide. The model is comprehensive, covering the singleproject perspective as well as the organization's business interests, including leadership and organizational long-term strategies. This is a multiproject perspective. PROPS is not only intended as a guide for the project manager, it is also a monitoring and control tool for managers at different levels in the organization (Räisänen and Linde 2004). PROPS describes what to do and when to do it, but not how to do it. This means that the model has to be adapted to new settings such as documents, tools, and best practice. These should be tailored for the needs of specific organizations.

The goal of the management change project studied was the redesign and implementation of PROPS at the Swedish Customs Authority. The case study focused on top management, the team in charge of the implementation, project managers using the model, the model (the ICT), and some major local settings. In all, 31 semi-structured interviews, as well as numerous informal discussions and mail conversations with topmanagement, members of the project office, project managers, and members of the project group have been carried out during 1999-2002, with follow-ups in 2004, 2006, 2007, and early 2008. Project-specific documentation and the PMM were analyzed. In addition, on-site observations at the project office, four local offices, and project group meetings were carried out in 19 visits to the organization.

In 1999, a decision was made to "projectify" the Swedish Customs Authority (i.e., to create an effective multiproject organization). To fulfil this goal, a project groupconsisting of representatives from head-office, local offices, and the IT department — was 
formed. The project manager was a top manager from the development department. The vision of this group was that the PROPS model would function as the intermediary through which the organization would govern all of its projects, support its project managers, and increase knowledge about handling project portfolios. As one of the initiators put it, PROPS would "bring order to their project organization." Thus the initial goal of the project was to implement PROPS within the organization.

In the early stage of the project, during the planning stage, the goal and task shifted focus from a straightforward implementation of the model and change of the organization to a redesign of the PMM. The new vision resulted in wide-ranging changes to the model enacted through multiple negotiations and realignments of spokespersons for and against it. To gain support for the PMM project and increase project management knowledge, specific PROPS courses were offered to relevant actors at all levels of the organization.

To help change the organization and to facilitate the implementation phase in the project, a new organizational unit, the project office, was created. As advocated by the PMM, their task was, in the long term, to function as a support unit for the projects in the organization and, in the short term, to support the transformation process in effective multiproject management. Members of the project office became an essential part of the implementation and organizational change.

Despite painstaking efforts to prepare for organizational change and to adapt the model to its new context, the actual implementation of the PMM generated many problems and caused enormous delays. At the beginning of 2002, a tentative model was finally launched on the intranet. However, a major part of the user test of the model and the implementation of organizational change was still incomplete. In 2004, the new multiproject management approach could finally be described as implemented, even though there were still ongoing activities related to adaptation and change. During the following years, there was a slow stabilization of use. From time to time, at least parts of the inherent ideas in the PMM were questioned and not everything went smoothly. However, the PMM project is seen and described as a success by the organization and the PMM perceived as a natural part of the ICT. Hence all major development projects and IT projects at the Swedish Customs Authority are now using the PMM. The project manager is an official and most wanted role, and all together the effect on the organization of the implementation of this model is substantial and can be found at all levels in the organization.

\subsection{The Telemedicine Project}

Telemedicine consists of IT applications supporting health-care services via electronic transmission of information or expertise in order to improve the effectiveness of resource utilization and allocation (Bashshur 1995). Generally, telemedicine is based on different video conferencing systems to which optical medical equipment can be connected to transmit live or still pictures. The general interest in telemedicine technology increased slowly in the early 1990s. In the mid-1990s, a boom could be witnessed regarding the number of telemedicine projects in the Swedish health care sector.

The methods used for studying the project were semi-structured interviews and participant observation between 1994 and 1999. A total of 63 interviews with medical specialists, general practitioners, hospital managers, and politicians were conducted. 
From 1994 through 1999, on-site observations were conducted at 18 meetings of the project group. Ten of the observations were done before the installation of the systems. After the first study, informal contacts have been kept with informants in the actual settings. Seven follow-up interviews have been conducted with representatives for the project settings studied between 1996 and 1998, with two managers at a central support function, and representatives from clinics that started using telemedicine after 2000. Additionally, document studies have been conducted and a database containing 1,650 telemedicine consultations that took place between June 2003 and January 2006 has been analyzed.

The country studied was an early adopter of telemedicine. In 1994, concrete general goals were identified for the coming telemedicine projects. The general goals are as follows: to increase value for patients through access to medical specialists irrespective of location; to support the development of competence in the organization; to decrease the costs of the county council; and to investigate the long-term effects telemedicine may have on the structure of health care in the county. A project group, consisting of physicians and personnel from the department of medical technology, looked for adequate equipment and planned for the introduction of the technology to determine the physical location and the need for education. In August of 1996, the telemedicine equipment was purchased and installed.

During the pre-study phase, two projects crystallized: general telemedicine (GTE) and telepathology (PAT). In both projects, the technical platform was a videoconferencing system that could be connected to medical equipment. The GTE project addressed communication between general practitioners at health centers and specialists at the county or university hospitals. The specialties involved were dermatology, orthopaedics, and otolaryngology. Most specialists were located at the university hospital; the orthopaedists were located both at the university and county hospitals. By connecting optical equipment to the video conferencing system, it was possible for general practitioners to examine, the ear or the skin of a patient and transmit pictures, live or still, to the specialists. The specialists could then advise the general practitioners about further treatment of the patient and whether the patient should be hospitalized.

The PAT project concerned communication between medical specialists, allowing gynaecologists and surgeons at a county hospital to communicate with pathologists and cytologists at the university hospital. In this case, there were two major applications. The first application was the remote examination of frozen sections and of cytological sections. The pathologists and cytologists at the university hospital could manoeuver a microscope placed at the county hospital. The microscope, connected to a video system, was used to examine the sections. The standard question from county hospital physicians was whether a section was malignant. The second application was to gain further information concerning the section samples sent from the county hospital using an expert consultation. When additional information was required, the pathologist at the university hospital could mobilize appropriate specialists and set up a videoconference.

Although telemedicine did not boom in terms of frequency of use during the first three years (1996-1998), the project was perceived as beneficial and the county management continued to fund further development. The technology had a spokesperson at the top management level, the research and development manager, who had a positive attitude toward new technologies and projects. Accordingly, today there are approximately 100 telemedicine units installed at health centers, hospitals, and administrative 
units. Furthermore, in 1999, a telemedicine center was established at the university hospital. The center should promote telemedicine use and be a support function for departments introducing the technology. However, the two people responsible for the center stated that it is hard to implement applications into ordinary routines. Often the projects ran very well, but when results were implemented in daily operations, it was much harder. They were still waiting for a breakthrough that would generate clear engagement from top management and department managers. However, in 2006, the manager for the telemedicine center stated that the county used telemedicine more than any other county in Sweden.

\section{WHERE ARE THE SPACES FOR INNOVATION?}

Earlier, we claimed that programs of action inscribed in an ICT bring more or less flexibility to the organization in which the ICT is deployed. In this section, we will analyze the spaces for innovation in the two cases studied by examining how the ICT was interpreted, how the organizations were changed, and if spaces for innovation were closed or maintained in order to achieve sustainable changes.

\subsection{Interpreting Spaces for Innovation}

The support for the idea to implement the PMM as a tool for an effective multiproject organization was strong in the organization and the ideas inscribed in the PMM of how such an organization would be constructed and organized were well described by the initial designers of the PMM. The designers of the PMM tried to create an ICT solution with limited space for innovation and one of their goals with this product was to create a standard for managing multiproject organizations (Räisänen and Linde 2004). However, when it comes to the implementing organization, the knowledge amongst users as well as management of the final effect of the PMM was notably unclear at the beginning of the implementation, as was the knowledge of the range of adaptations and development to be done before the model could be an effective tool in the organization. Hence there was an initial planned approach to the implementation with a group from different parts of the organization, a redesigner group, engaged to make changes in the PMM and then implement it. Notable is that there was no detailed plan from management on how this implementation actually should be carried out. However, the redesigner group had to interpret the PMM as a whole, the text inscribed, and the context. Even if the intended result of that process was to create a PMM that reflected management ideas of how to do things, the process ended with only slight modifications when compared to the original model. It became clear that in order to fully understand the PMM and its complexity, and further to decide what changes to make both in the PMM as well as in the organization, the process needed to be divided into several steps and more potential future users had to be engaged. The power of the interpretation of the model had to be handed over to the new actor groups in the organization, the users.

In the telemedicine case there was, as in the PMM case, at the outset a consensus among actor groups concerning the overall goals. However, there were not many clear 
ideas of what should be done in order to achieve a change and what arrangements were needed to accomplish a sustainable change. The uncertainty of what should be done can be seen as a consequence of the technology designers' delegation of a rather large space of innovation to the adopting organization (i.e., to identify and decide on an appropriate uses of the technology). Furthermore, it was delegated to the adopting organization to identify how to make use compulsory if indeed a change was wanted. Nevertheless, ideas soon took shape when the clinics of dermatology, otolaryngology, orthopaedics, surgery pathology, and cytology, together with two remote health centers, were included in the first stages of the project. Consequently, there were two central ideas. First, health centers should have the opportunity to consult medical specialists to discuss the further treatment of a patient, for example, whether the patient should be sent to the hospital a few hundred kilometers away. Second, medical specialist (surgeons) at a county hospital should have the option to receive urgent answers on frozen tissues from pathologist or cytologists, in order to make decisions on how to proceed with surgery. Still, it was unclear what should be done in order to come closer to the goals expressed.

The insight that that technology designers had delegated to user to innovate applications for the technology was rather clear among the actor groups involved. In interviews, hospital managers clearly expressed that it was the physicians' responsibility to find out how the technology would be used. This activity would, furthermore, be a part of physicians' ordinary development duties. In this sense, no further spaces for innovation were created. Physicians in the project group were well aware of the fact that they had precedence of interpretations regarding the innovation of telemedicine applications. This belief was so deeply rooted that three smaller teams were created in the GTE project, before the equipment was installed, in order to find out in which situations technology could be used in the different medical specialties. Rather soon, however, an insight developed of the necessity to test and experiment with the technology in order to find appropriate applications and how to organize activities. In the PAT project, the project manager had a clear idea of two applications and he had even developed a flowchart of how activities would be organized.

\subsection{Changing the Organization by Innovation, Restriction, or Alignment}

When looking into the further change process when the PMM was diffused and used throughout the organization, it was clear that the designers and the management in the organization had succeeded in the way that the space for interpretation concerning "what to do" was limited, or even accepted to a degree of irreversibility. However, how to carry out specific work procedures that were stipulated in the PMM, changing the organization, etc. (i.e., how to do activities) was still to be innovated and decided by management and users during the implementation and practical use. Several actors and actor groups felt that they had the responsibility and legitimacy to interpret the PMM and decide not only how to use the model and for what, but also to identify work procedures in detail. During the first years, the presence of spokespeople in local contexts had a significant influence on the frequency of use of the PMM and change in behavior and work structures. Networks representing different interpretations of the new model could be found in 
different projects, departments, and groups crossing organizational boundaries, all struggling to make their ideas of multiproject organizing the common view. Most of these networks were represented by enthusiastic actors, holding high positions in the organizational hierarchy. Their power positions provided them with the legitimacy needed to interpret "how to do," and the space to experiment with and develop the technology, as well as to prescribe routines that supported inscriptions in the PMM. Furthermore, they also could grant similar privileges to their colleagues, which helped to strengthen the ideas inscribed in the PMM. The major actor groups with clear precedence of the interpretation of the PMM were the redesign group, key people at the project office, the top manager in the IT department, and some successful project managers.

However, the space for interpretations and innovation had to be reduced if the intended control of the project organization was to be reached. The project management office was established at the start of the implementation by the management of the organization. The project office was responsible for the official ideas of how to use the model and how and what to change. The project office was the main tool for management to control and restrain the interpretation of the PMM and, through negotiation processes with those different actors and actor groups discussed above, reach a consensus. Another essential part of the process for the development and stabilization of new work procedures was the establishment of a group of professional project managers. Those project managers became and still are the main carrier of the ideas inscribed in the PMM, tightly connect to the project management office and, by that, also related to the management of the organization.

If the possibilities for a broad range of interpretations and use of the implemented PMM on an overall level were quite restricted in the PMM case and the focus was on how to carry out activities, it was very much the opposite in the telemedicine case.

Spaces for innovation, regarding the appropriation of telemedicine, were considered to be rather large by physicians. For example, the project manager stated that "it is only your imagination that puts the limits." A physician stated that "you always have to take into consideration when you can do a consultation in order to test the limits." Accordingly, the project in some settings was characterized by testing what could be done with the telemedicine technology. These activities continued after the first project was finished, but the entire time they were dependent upon the will of single individuals. However, after the first project finished, the county management gradually increased the spaces for innovation by continuously investing in new equipment and upgrading existing equipment. Furthermore, the county management maintained spaces for innovation on the county level by the foundation of the TeleMedLab in 1999. This department proactively works for the dissemination of telemedicine use in the county by testing new equipment, supporting clinics in testing and implementing the technology, and maintaining and upgrading existing equipment.

In the PAT project, the idea of how to organize the use of telemedicine was relatively clear, which can be seen as consequence of the clearly defined applications. This, in many ways, was an opposite situation compared to the PMM case. However, in the GTE project, and for some years after the project, the issue of how to organize the use of telemedicine shifted back and forth. In the early stages of the project, opinions shifted between planned and urgent/ad hoc consultations. At the outset, planned consultations were considered as the best way of organizing consultations, probably due to the fact that 
other activities was organized in this mode. But after a year and visits at a few demonstrations of the equipment, the project group decided that most consultations should be ad hoc, mainly because patients and general practitioners would gain immediate benefits. The consultations between general practitioners and dermatologists, however, needed to be planned beforehand, due to the dermatologists not having their own equipment.

Ad hoc consultations could be a way of improving health care services for patients in rural areas, as well as general practitioners for getting immediate feedback on their opinions, but not taken into considerations was that $a d$ hoc use would require spaces for innovation for the actor groups concerned in order to change work procedures to fit this way of working. The need to change routines became obvious when general practitioners complained about the time that they needed to spend on "chasing" medical specialists at the university hospital, or when medical specialists had difficulties because they were called away from the activities with which they were occupied when a request from an ad hoc consultation emerged. Furthermore, a general practitioner claimed that ad hoc use would have required changed views on roles and relationships between primary care and hospital care. Suddenly primary care could put demands on hospital care, making it a service provider to primary care. Even if this interpretation not was verbalized among medical specialists, telemedicine is gradually being reinterpreted as something that medical specialists use for offering services to other hospitals. When the use between June 2003 and January 2006 is studied, 72 percent of the 1,650 consultations conducted were initiated from a hospital and 60 percent of that is with other hospitals. Only 10 percent of the consultations are initiated from a health center dealing with clinical issues. In this way, the need for organizational innovations and rethinking of roles and relationships among actor groups is decreased. Deployment of the technology can now follow prevailing routines that just have to be modified to the new medium

\subsection{Closing, Maintaining, or Ignoring Spaces for Innovation}

By following the deployment of telemedicine over 14 years, we see that use can fade away as suddenly as it emerged. Among the eight settings involved at the outset, telemedicine is today actively used in three settings, all at hospitals, and the heavy users are clinical or laboratory departments. The exploration of the quite large space for innovation given to users and management was, at the outset, mostly reinforced by the idea of ad hoc use. But the need for organizational innovations made the telemedicine drift toward planned use that can be seen as an adaptation to existing routines (see Holmström and Stadler 2001). Accordingly, how the technology is used today has been standardized, but what the technology is used for is more diversified. The use varies considerably from setting to setting and the challenge for actor groups involved is to maintain a sustainable change triggered by the use of telemedicine. However, the county management has tried to keep the spaces for innovation open by investing in equipment and in the TeleMedLab. In this sense, no unified use is strived for.

In the PMM case, the situation is to some degree much opposite. The ideas inscribed in the PMM and the change to a multiproject organization seems to be well established even if far from everything inscribed in the PMM is used or used as intended, and much more than intended is handed over to actor groups like the project managers to decide. 
Hence the ideas of projects as a work-form and project managers as an established professional role are totally accepted and integrated in the management of the organization. Rules and regulations have been added and adapted over the years by top management to enforce the ideas represented in the PMM and, in addition, courses related to ideas promoted in the PMM have been given to the employees, all examples of action taken by management to keep control. However, the implemented change is no longer directly dependent on the actual ICT, the PMM; it is integrated in the work culture and by that it probably would be hard and complicated to take away even if some of the changes fade and the PMM is no longer used. In that sense, this is a successful implementation that could be described as a translation that reached a point of stabilization.

\section{CONCLUDING DISCUSSION}

The aim of the paper has been to analyze how features of an ICT shape actor groups' options and possibilities to innovate in ICT-triggered change processes. We have described two ICT implementation processes in which programs of actions inscribed in the ICT were interpreted, changed, and put into use by actor groups. We have argued that ICT systems contain programs of action that either could give considerable spaces for innovation when the technology is deployed, or that are rather restricting. Based on the analysis, we have identified three dimensions of inscribed programs of action to be sorted out. These dimensions could also be considered different levels in an interpretation process of an ICT. The first dimension concerns actors' interpretations if they have a choice to use the ICT. For the second dimension, if actors' choose to, or must, use the ICT, what alternatives for usage exit, or could exist? The third dimensions concerns how detailed, or limited, the system is in how activities should be conducted. Based on our findings and elaborating on ideas presented by Akrich (1992), Hanseth and Monteiro (1997), and Linderoth (2000), the three dimensions are labeled

- Use/not use: To what extent does a program of action give flexibility in choice of acceptance of usage or rejection of usage of that specific program of action?

- What to do: To what extent does the program of action allow flexibility of usage alternatives?

- How to do: To what extent does the program of action allow flexibility in how activities will be conducted?

The first dimension, use/not use, is the key to understanding the change process and the key for management in the organization to control, in order to generate any action at all. This flexibility is connected to the entire ICT system, as well as to single programs of action. In both of the cases we studied, actors had at the outset significant flexibility in the choice of using the system or not. In the PMM case, however, flexibility in the dimension use/not use diminished, on an overall level, when the implementation proceeded. Management was rather successful in strengthening the use dimension through regulations, connecting the PMM to trends in society and connecting the use of the PMM to powerful role models, which made rejection of the PMM and resistance to change nearly impossible. In the telemedicine case, programs of action also gave management 
an opportunity to delimit the choices of use/not use. However, this opportunity was not given attention nor understood. This implied that the precedence of interpretation of whether the technology would be used or not was handed over to actors in local settings where the technology was deployed.

In the second and third dimension, what to do and how to do, there are some basic differences between the cases, with regard to how inscribed programs of action shaped actor groups' spaces of innovation. The PMM model prescribed rather detailed what to do in order to create and manage an efficient multiproject organization, while in the telemedicine case, what to do was based on some generic interpretations in the organizational field, implying that innovating what to do is a prerequisite for a change process to proceed. This means that, in the first case, designers successfully and consciously have allowed room for interpretation and delimited the space for innovation, while in the latter case there were no such aspirations from the designers.

However, in the third dimension, the situation was the opposite. In the PMM case, the designers have delegated to management and users innovation on how to use the model. However, space for innovation is also inscribed in the model, because the user and management have to innovate in order to able to use the model and achieve the desired change. On the other hand, in the telemedicine case, the technology designers had clear ideas on how to use the technology: actors in two, or more, sites are mutually present and solving whatever issues they want and it can be beneficial to transmit live or still pictures in order to ease the solving of issues.

Furthermore, against the previous discussion, it is of great importance to emphasize that the idea of a classification of the programs of actions that are inscribed in the technology should not be misinterpreted as some kind technology determinism. Instead, we have showed that an ICT consists of a mixture of inscribed programs of actions that both allow considerable space for innovation, as well as notable limited space for innovation and flexibility. Hence, these programs of action are not fixed but need to be put into relation to the interpreter and the context. This implies that the ICT, in order to be manageable and an implementation and change able to forecast the ICT, has to be analyzed in its context and situation. Considerable action must be taken by management in the organization in order to balance the space of innovation to the possibilities to control and forecast.

\subsection{Who Controls Spaces of Innovation?}

As discussed, the programs of action have implications for different actor groups' possibilities to exercise power on the ICT-triggered change process and the space for innovation. In the cases studied, actor groups' possibilities to exercise power over the process shifted back and forth between designers, managers, and users over time and with regard to what dimension of programs of action are in focus (see Figure 1).

The shifting power is also a consequence of the spaces of interpretation given to, or taken by, different actors groups. A generic ICT gives users and management large spaces of interpretation, implying that use can be very disparate and leading to varying transformation of organizational units. On the other hand, if spaces for interpretation are limited, the organizational transformation can be unified, but the actors can refuse to use 


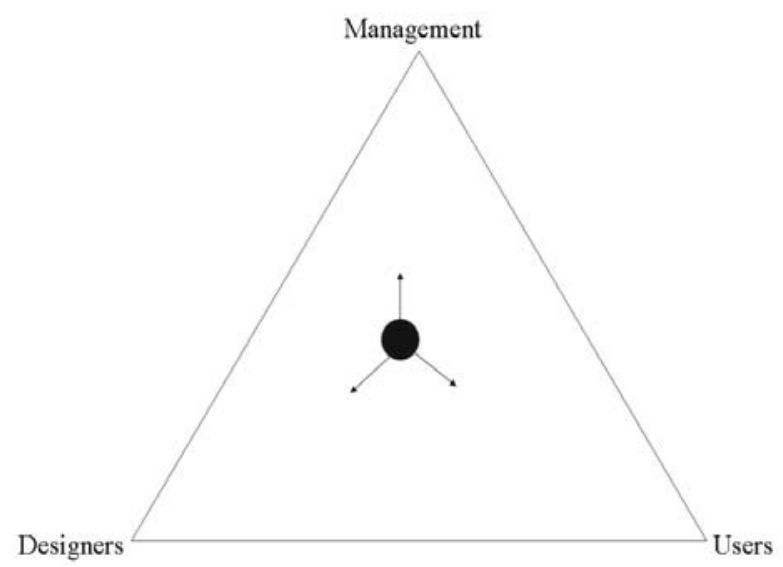

Figure 1. Shifting Power over ICT-Mediated Change Processes

the ICT due to the limited spaces for interpretation. However, in order to make the change process proceed and reach some kind of unified transformation of an organization, alliances are needed among actor groups from time to time. For example, management and users need to accept how ICT should be used, management needs to keep user spaces for innovation, for example, by investing in more equipment or funding support functions (see Linderoth 2007).

To conclude, trying to delimit the space for innovation also delimits the development potential in the organization and it could also increase resistance to change while the power of the interpretations obviously is not in the hands of the user. On the other hand, a high grade of flexibility could result in such disparate use of the ICT that the overall aim of the implementation and change is jeopardized or that the matter of changing behavior and work procedures and any use of the ICT could be ignored without consequences. From a development and an innovation perspective, this is a dilemma.

\section{References}

Akrich, M. 1992. "The De-Scription of Technical Objects," in Shaping Technology/Building Society, W. E. Bijker and J. Law (eds.), Cambridge, MA: MIT Press, pp. 205-224.

Bashshur, R. L. 1995. "On the Definition and Evaluation of Telemedicine," Telemedicine Journal (2:1), pp. 19-30.

Berg, M. 1997. "Of Forms, Containers, and the Electronic Medical Record: Some Tools for a Sociology of the Formal," Science, Technology, and Human Values (22:4), pp. 403-423.

Boland Jr., R. J., Lyytinen, K., and Yoo, Y. 2007. "Wakes of Innovation in Project Networks: The Case of Digital 3-D Representations in Architecture, Engineering, and Construction," Organization Science (18),pp. 631-647.

Bridgman, T., and Willmott, H. 2006. "Institutions and Technology_Frames for Understanding Organizational Change: The Case of a Major ICT Outsourcing Contract," The Journal of Applied Behavioral Science (42:1), pp. 110-126. 
Ciborra, C. U. 1996. "Introduction: What Does Groupware Mean for the Organizations Hosting It?," in Groupware and Teamwork, C. U. Ciborra (ed.), Chichester, UK: . John Wiley \& Sons, pp. 1-19.

Davidson, E. 2006. "A Technological Frame Perspective on Information Technology and Organizational Change," The Journal of Applied Behavioral Science (42:1), pp. 23-39.

Elbanna, A. R. 2008. "Strategic Systems Implementation: Diffusion Through Drift," Journal of Information Technology (123:2), pp. 89-96.

Gunnarsson, S., Linde, A., and Loid, D. 2000. "Is Standardization Applicable to Project Managers of Multi-Project Companies?," in Paradoxes of Project Collaboration in the Global Economy: Interdependence, Complexity and Ambiguity, in Proceedings of the IRNOP IV Conference: Paradoxes of Project Collaboration in the Global Economy: Interdependence, Comlexity and Ambiguity, The International Research Network on Organizing by Projects, Sydney, Australia, January 9-12, pp. 136-146.

Hanseth, O., and Braa, K. 1998. "Technology as a Traitor: Emergent SAP Infrastructure in a Global Organization," in Proceedings of the $19^{\text {th }}$ International Conference on Information Systems, R. Hirschheim, M. Newman, and J. I. DeGross (eds.), Helsinki, December, pp. 188-197.

Hanseth, O., and Monteiro, E. 1997. "Inscribing Behavior in Information Infrastructure Standards.," Accounting, Management \& Information Technology (7:4), pp. 183-211.

Holmström, J., and Stadler, F. 2001. "Drifting Technologies and Multi-Purpose Networks: The Case of the Swedish Cashcard," Information and Organization (11:3), pp. 187-206.

Latour, B. 1992. "Where Are the Missing Masses? The Sociology of a Few Mundane Artifacts," in Shaping Technology/Building Society, W. E. Bijker and J. Law (eds.), Cambridge, MA: MIT Press, pp. 225-258.

Linderoth, H. C. J. 2000. Från vision till integration - Infusion av telemedicin, en översättningsprocess, unpublished Ph.D. thesos, Umeå School of Business, Umeå University.

Linderoth, H. C. J. 2007. "Make Technology Invisible, or Keep it Visible: The Role of Technology in Intra-Organizational Transfer and Integration of Project Outcomes," in Organizational Dynamics of Technology Based Innovation: Diversifying the Research Agenda. T. McMaster, D. Wastell, E. Ferneley, and J. I. DeGross (eds.), Boston: Springer, pp. 267-283.

Linderoth, H. C. J., and Pellegrino, G. 2005. "Frames and Inscriptions-Tracing a Way to Understand IT-Dependent Change Projects," International Journal of Project Management (23:5), pp. 415-420.

Lundin, R. A., and Söderholm, A. 1995. "A Theory of the Temporary Organization," Scandinavian Journal of Management (11:4), pp. 437-455.

Monteiro, E. 2000. "Actor-Network Theory," in from Control to Drift: The Dynamics of Corporate Information Infrastructure, C. U. Ciborra (ed.), Oxford, UK: Oxford University Press, pp. 71-83.

Monteiro, E., and Hanseth O. 1995. "Social Shaping of Information Infrastructure: On Being Specific about Technology," in Information Technology and Changes in Organizational Work, W. J. Orlikowski, G. Walsham, M. R. Jones, and J. I. DeGross (eds.), London: . Chapman \& Hall, pp. 325-343.

Orlikowski, W. J. "Improvising Organizational Transformation Over Time: A Situated Chagne Perspective," Information Systems Research (7:1), pp. 63-92.

Orlikowski, W. J., and Iacono, S. 2001. "Research Commentary: Desperately Seeking the 'IT' in IT Research - A Call to Theorizing the IT Artifact," Information Systems Research (12:2), pp. 121-134.

Orlikowski, W. J., and Gash, D. 1994. "Technological Frames: Making Sense of Information Technology in Organizations," ACM Transactions on Information Systems (12:2), pp. 174-207.

Orlikowski, W. J., and Yates, J. 2006. "ICT and Organizational Change - A Commentary," The Journal of Applied Behavioral Science (42:1), pp. 127-134. 
Räisänen, C., and Linde, A. 2004. "Technologizing Discourse to Standardize Projects in MultiProject Organizations: Hegemony by Consensus?," Organization (11), pp. 101-122.

Rosenberg, N. 2000. Inside the Black Box.: Technology and Economics, Cambridge, UK: Cambridge University Press.

\section{About the Authors}

Anneli Linde is based at Umeå School of Business, Umeå University, in Sweden. Her research focuses on the development, implementation, and use of IT-based management systems in multiproject organizations and she has several publications in this area. Anneli is currently completing her Ph.D. based on comprehensive case studies on ICT-mediated change processes. Anneli has extensive experience teaching management and leadership and obtained a position as lecturer at Umeå University. In addition, she currently holds a grant for researching the construction sector, focusing on the relation between ICT and sustainability and environmental issues. She can be reached by e-mail at anneli.lindeusbe.umu.se.

Henrik Linderoth, Ph.D., holds a position as assistant professor at Umeå School of Business, Umeå University. His research interest is primarily focused on ICT-triggered change processes and consequences of projects as a form for organizing activities in an organization. Henrik has done studies of ICT use in the health care sector and is currently studying ICT use in the building and construction sector. He can be reached by e-mail at henrik.linderoth@usbe.umu.se. 